\title{
Where there's smoke, there's fuel: predicting Great Basin rangeland wildfire
}

Joseph T. Smith ${ }^{\mathrm{a} 1}$, Brady W. Allred ${ }^{\mathrm{a}, \mathrm{b}}$, Chad S. Boyd ${ }^{\mathrm{c}}$, Kirk W. Davies ${ }^{\mathrm{c}}$, Matthew O. Jones ${ }^{\mathrm{a}}$, Andrew R. Kleinhesselink ${ }^{a}$, David E. Naugle ${ }^{b}$

a Numerical Terradynamic Simulation Group, University of Montana, Missoula, MT 59812, USA

b W.A. Franke College of Forestry and Conservation, University of Montana, Missoula, MT 59812

c US Department of Agriculture, Agricultural Research Service, Burns, OR, 97720

\section{Abstract}

Wildfires are a growing management concern in western US rangelands, where invasive annual grasses have altered fire regimes and contributed to an increased incidence of catastrophic large wildfires. Fire activity in arid, non-forested regions is thought to be largely controlled by interannual variation in fuel amount, which in turn is controlled by antecedent weather. Thus, long-range forecasting of fire activity in rangelands should be feasible given annual estimates of fuel quantity. Using a $32 \mathrm{yr}$ time series of spatial data, we employ machine learning algorithms to predict the relative probability of large (>400 ha) wildfire in the Great Basin based on fine-scale annual and 16-day estimates of cover and production of vegetation functional groups, weather, and multitemporal scale drought indices. We evaluate the predictive utility of these models with a leave-one-year-out cross-validation, building spatial forecasts of fire probability for each year that we compare against actual maps of large wildfires.

Herbaceous vegetation aboveground biomass production, bare ground cover, and long-term drought indices were the most important predictors of fire probability. Across 32 fire seasons, $>80 \%$ of the area burned in large wildfires coincided with predicted fire probabilities $\geq 0.5$. At the

\footnotetext{
${ }^{1}$ Corresponding author: Joseph T. Smith, joe.smith@umontana.edu
} 
scale of the Great Basin, several metrics of fire season severity were moderately to strongly correlated with average fire probability, including total area burned in large wildfires, number of large wildfires, and average and maximum fire size. Our findings show that recent years of exceptional fire activity in the Great Basin were predictable based on antecedent weather and biomass of fine fuels, and reveal a significant increasing trend in fire probability over the last three decades driven by widespread changes in fine fuel characteristics.

\section{Keywords}

Cheatgrass; drought; fire; fuels; Great Basin; productivity.

\section{Introduction}

Shifting fire regimes in western North America present rapidly escalating management challenges. Driven by a growing human population, climate and land use change, exotic species, and historical fire suppression, the annual area burned and incidence of very large wildfires have risen in recent decades (Dennison et al. 2014, Westerling 2016). Though current rates of wildfire, broadly aggregated, are within or below the long-term (i.e., millennial scale) range of variation due to a century of aggressive fire suppression (Marlon et al. 2012), humans have increased ignitions (Balch et al. 2017), altered fuel characteristics (Noss et al. 2006, Balch et al. 2013, Fusco et al. 2019), and otherwise modified fire regimes of many western ecosystems, with long-term impacts that can include permanent vegetation state transitions (D’Antonio and Vitousek 1992, Coop et al. 2020) and degradation or loss of habitat for sensitive species (Rockweit et al. 2017, O'Neil et al. 2020). Responding to these trends and threats, the US federal fire suppression budget has grown more than six-fold in the past three decades, from an average of $\$ 370 \mathrm{M} \mathrm{yr}^{-1}$ from $1985-1989$ to $\$ 2.38 \mathrm{~B} \mathrm{yr}^{-1}$ from 2016-2020 (National Interagency Fire Center, 2021). 
Although forest fires have historically been the focal point of fire management and research, increasing wildfire in non-forested ecosystems across western North America (hereafter rangelands) is a growing concern. The Great Basin, a cold desert covering most of Nevada and parts of California, Idaho, Oregon, and Utah, has experienced particularly severe fire seasons in the past decade fueled in part by exotic annual grasses such as cheatgrass (Bromus tectorum L.; Balch et al. 2013, Fusco et al. 2019). Native vegetation communities of the Great Basin, co-dominated by perennial grasses and non-resprouting shrubs such as sagebrush (Artemisia spp.), historically experienced infrequent fire and can take many decades to recover after burning. Larger and more frequent wildfires therefore threaten to catalyze widespread, permanent shifts to vegetation communities devoid of shrubs and dominated by exotic annual grasses, with negative consequences for rural communities and shrubland obligate species (Knick et al. 2003, Coates et al. 2016, O’Neil et al. 2020).

Long-range forecasts of fire activity, available months in advance of the fire season, would allow resource managers to anticipate, plan for, and mitigate severe fire conditions. Increasingly, widespread and synchronous fire activity throughout western North America exceeds fire suppression capacity (Podur and Wotton 2010, Abatzoglou et al. 2021), contributing to increased incidence of wildfire disasters and underscoring the need for accurate, long-term forecasts to guide management and allocation of fire suppression resources. Currently available indices of fire danger are short-term, reflecting current conditions or forecasting a few days in advance, and based largely on fuel moisture and fire weather (e.g., the Keetch-Byram Drought Index, Burning Index, Energy Release Component, and Fire Potential Index; Keetch and Byram 1968, Burgan et al. 1998). These tools are critical for informing the public of immediate fire danger, coordinating fire suppression resources in response to rapidly changing conditions during the fire season, and fighting fires, but do not provide the advanced warning needed to implement targeted fuel management, strategically site fuel breaks, or seek additional funding to support local preparedness. 
In rangelands, however, it may be possible to accurately forecast the likelihood of large wildfires months in advance. Though climate and weather exert strong control on fire across ecosystems (Littell et al. 2009), the nature of this relationship differs between forest and rangeland ecosystems (Krawchuk and Moritz 2011, Abatzoglou and Kolden 2013, Abatzoglou et al. 2018). Semi-arid and arid rangeland ecosystems are primarily "fuel-limited" in the sense that climate-driven variation in primary production determines whether adequate fuel is present to carry fire. This contrasts with forested ecosystems, where fuel is consistently abundant but varies in moisture content, and are therefore considered "flammability-limited" (Abatzoglou and Kolden 2013). In rangelands, fire activity is strongly correlated with antecedent conditions (i.e., conditions prior to the onset of the fire season) affecting fuel growth, and weakly related to weather during the fire season (Westerling et al. 2002, 2003, Brown et al. 2005, Littell et al. 2009). Indeed, Pilliod et al. (2017) found antecedent precipitation, but not temperature, drove variation in fine fuels and was useful in predicting the number of large fires and total burned area over a 26 year period in the northern Great Basin, and found good agreement between long-term precipitation-based fire risk maps and locations of large fires across the Great Basin.

Although the links between precipitation, fuels, and fire in the Great Basin have largely been established (Westerling et al. 2003, e.g., Pilliod et al. 2017), long-range spatial fire forecasting has been hampered by a lack of data quantifying spatially variable and temporally dynamic fine fuels. Although currently available long-range outlooks exploit precipitation and drought indices as correlates of fine fuel growth, direct estimates of vegetation cover and/or production would better account for fine-grained variation induced by topography, soils, invasion by exotic annual grasses, and legacies of management and disturbance. This barrier has only recently been surmounted with the development of remote-sensing products based on the Landsat imagery record and providing annually-updated, high-resolution spatial estimates of herbaceous, shrub, and tree cover and production over the coterminous U.S. from 1984present (Jones et al. 2018, 2021, Allred et al. 2021). 
Our objective was to combine these high-resolution $(30 \mathrm{~m})$, dynamic maps of vegetation and moderate-resolution $(4 \mathrm{~km})$ weather data with machine learning to construct fine-scale rangeland fire forecasts for the Great Basin, and to evaluate the predictive accuracy of these forecasts in time and space. Numerous factors, many unrelated to fuels and subject to change over time (e.g., ignition probability may change with land use), influence the 'switches' that together determine where and when large wildfires occur (Balch et al. 2018). Our objective was not to account for all of these factors, but to produce an annual, fuel-based index of relative fire probability for the upcoming fire season at a fine spatial resolution and to explore the extent to which fuels explain the spatial and temporal patterns of wildfire in the Great Basin.

\section{Methods}

\section{Study area and data sources}

We focused our analysis on rangeland land cover as defined by Reeves et al. (2011) in the Great Basin (Fig. 1). We used EPA Level III ecoregions (Omernik and Griffith 2014) to define the boundaries of our study area, which included the Central Basin and Range, Northern Basin and Range, and Snake River Plain ecoregions. We sought to predict the occurrence of wildfire at the pixel level based on antecedent cover and net primary production of vegetation functional groups (perennial forbs and grasses, annual forbs and grasses, shrubs, litter, bare ground, and trees), weather (precipitation, temperature, and drought), and climate (Table 1). 

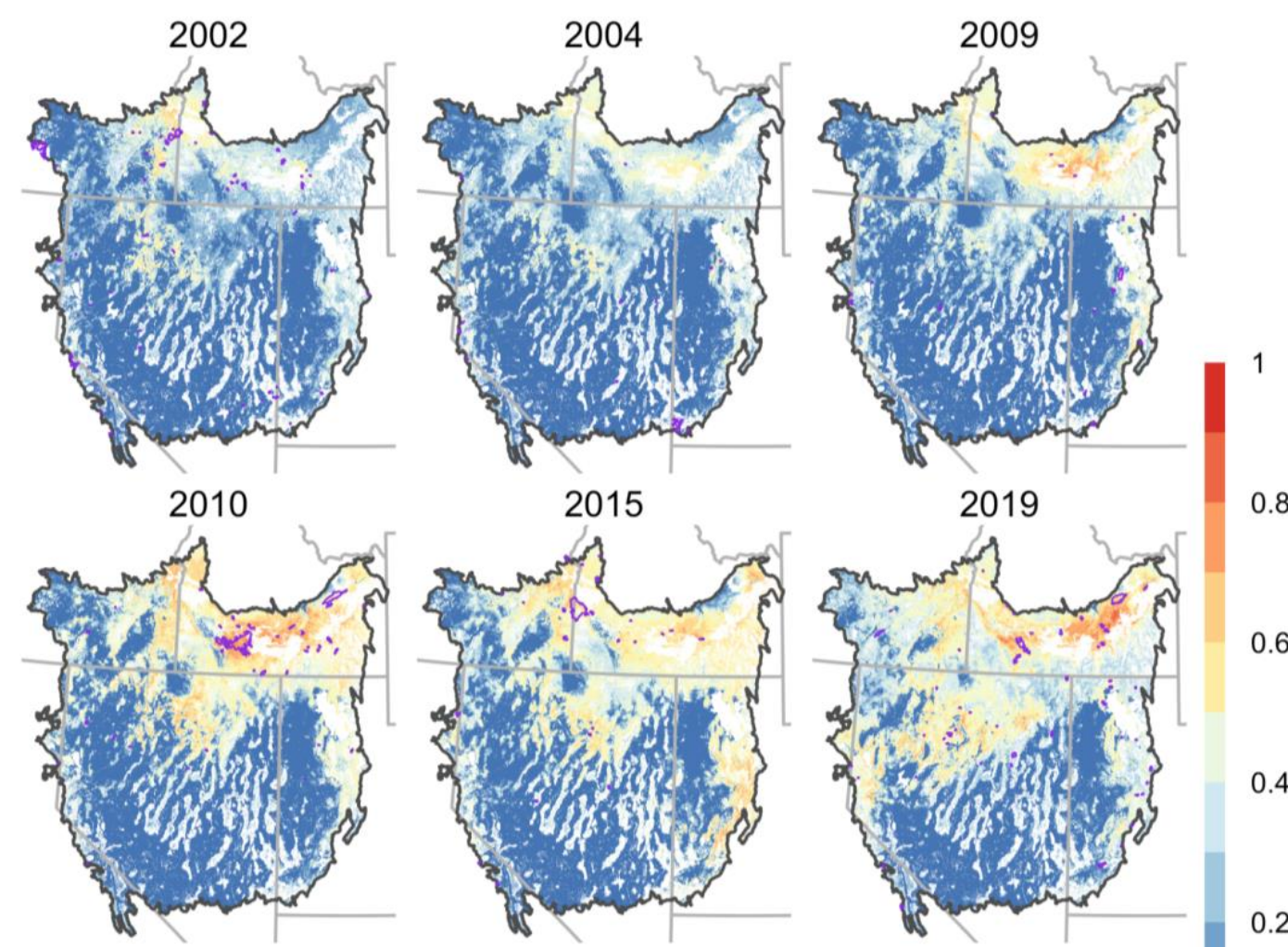

0.8
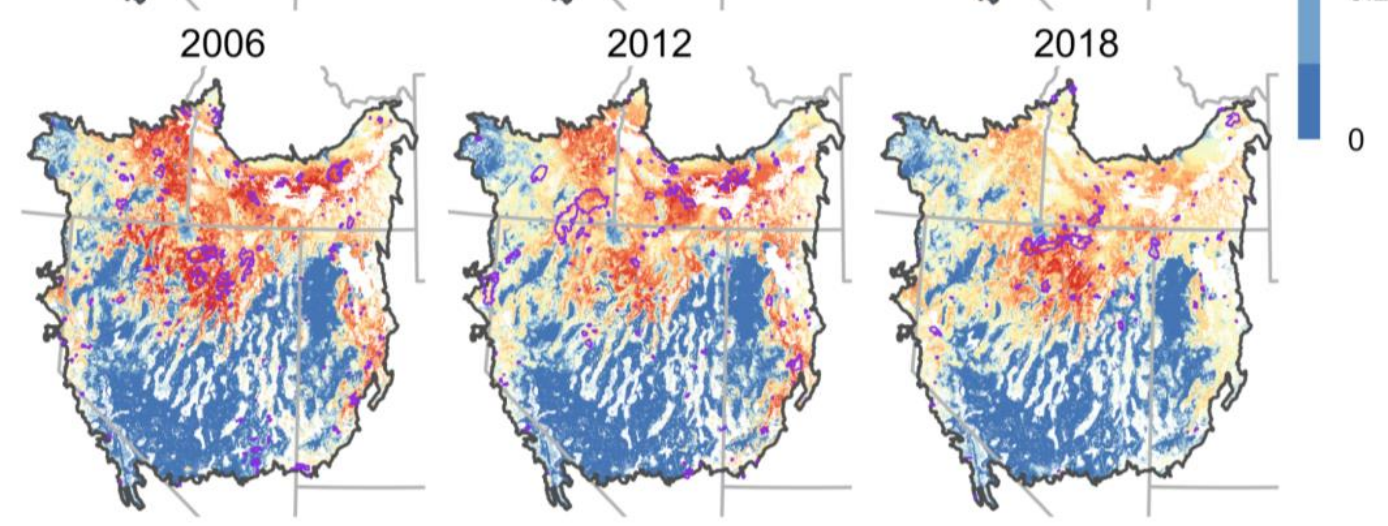

Figure 1. Maps of relative probability of large wildfire in the Great Basin, USA, predicted by random forest models using antecedent cover and production of vegetation, multitemporal scale drought indices, and bioclimatic variables. Perimeters of large wildfires are shown in purple. A leave-one-out approach was used to generate predictions for each year, with that year's data withheld from model training. Three recent (since 2000) years of low $(<0.22$; top row), moderate (0.22-0.35; middle row), and high ( $>0.35$; bottom row) mean fire probability were selected for illustrative purposes. An animation of the full time series, 1988-2019, is available online (https://rangelands.app/great-basin-fire/). 
Estimates of vegetation cover (percent), annual production (Ibs ac$\left.{ }^{-1}\right)$, and short-term production (lbs ac ${ }^{-1} 16-\mathrm{d}^{-1}$ ) were derived from the Rangeland Analysis Platform (Jones et al. 2018, 2021, RAP; Allred et al. 2021). Annual cover and production, which are updated each year in early spring with estimates for the previous year's growing season, were included at 1 and 2-yr lags; i.e., we used cover and production in year $t-2$ and $t-1$ to predict the occurrence of fire in year $t$. We used short-term (16 d) production of annual and perennial herbaceous functional groups to quantify cumulative production of fine fuels in year $t$ up to the date the forecast was made; this RAP data product is updated as provisional Landsat images are made available. For a specific April forecast, cumulative production is the sum of all short-term production estimates from Jan 1 through the date of the April forecast.

Water availability is a dominant control on primary production in most terrestrial ecosystems (Churkina and Running 1998), and precipitation is the primary driver of interannual variation in herbaceous vegetation cover in Great Basin rangelands (Pilliod et al. 2017). We included precipitation and drought variables derived from the gridded surface meteorological dataset (gridMET; Abatzoglou 2013) as indicators of resource availability for vegetation growth at multiple temporal scales. Although the Palmer Drought Severity Index (PDSI; Palmer 1965) has historically seen wide use in fire forecasting (Westerling et al. 2002, 2003), newer drought indices have been developed that allow drought to be quantified over various user-specified temporal scales. We explored two of these indices, the standardized precipitationevapotranspiration index (SPEI; Vicente-Serrano et al. 2010) and evaporative demand drought index (EDDI; Hobbins et al. 2016, McEvoy et al. 2016), calculated at 30 d, 90 d, 180 d, 270 d, 1 $\mathrm{yr}$, and $2 \mathrm{yr}$ temporal scales. The SPEI and EDDI both range from approximately -2 to 2 , but their interpretations are opposite: negative values of SPEI indicate drought, whereas negative values of EDDI indicate wetter conditions (less evaporative demand). These indices are updated every 5 days and are available for the period 1980-present. 
Low temperature limits vegetation growth during a significant portion of the year in the Great Basin. With adequate moisture, more rapid spring warming should facilitate faster vegetation growth and result in greater accumulation of fine fuels. We therefore calculated accumulated growing degree days (gdd) from January 1 to the date of the forecast using daily minimum and maximum temperatures from gridMET.

Climate may directly or indirectly influence the annual probability of fire. Direct effects include variation in the annual number of days with weather conducive to wildfire ignition and spread or timing of herbaceous vegetation senescence. Climate may indirectly affect annual probability of fire through effects on vegetation community composition. Vegetation communities occupying different biophysical settings will differ in their responses to precipitation, temperature, and drought. To account for this spatial climate variation, we included 19 standard bioclimatic variables from the WorldClim dataset (Hijmans et al. 2005).

We derived the categorical response, burned $(y=1)$ or unburned $(y=0)$ from the Monitoring Trends in Burn Severity dataset (MTBS; Eidenshink et al. 2007). MTBS maps all fires $>400$ ha (>1000 ac) since 1984 across all land ownerships. Unburned inclusions often occur within fire perimeters (Kolden et al. 2012), introducing opportunity for class label errors. Therefore, we used the MTBS thematic burn severity dataset to assign each pixel to the burned or unburned class. Thematic burn severity classes 1-5 indicate increasing burn severity. We assigned all pixels in burn severity class 1 or outside fire perimeters to the unburned class $(y=$ 0 ), and all pixels in classes $2-5$ to the burned class $(y=1)$. Class 6 represents pixels of unknown burn severity within fire perimeters. We assumed most pixels in class 6 in the Great Basin were assigned this class due to imagery issues (e.g., clouds or shadows), not because they were unburnable land cover types such as large water bodies; unburnable land cover types were already excluded from our analysis. Therefore, we assigned pixels in class 6 to the burned class. All data were accessed via Google Earth Engine (GEE; Gorelick et al. 2017), and all analyses (except tuning, see below) were conducted using the GEE code editor. 


\section{Model structure}

We used random forest models (RF; Breiman 2001) to predict the relative probability of burning. Random forests are widely used for prediction in ecology because they are relatively straightforward to fit, require little tuning, and readily accommodate non-linear relationships and interactions among predictors (Cutler et al. 2007). Random forest models have been applied to prediction of wildfire occurrence with success, achieving better performance than multiple regression models (Oliveira et al. 2012). Additionally, random forests generally perform well at predicting probabilities (Niculescu-Mizil and Caruana 2005).

Like many classification algorithms, however, $R F$ performance is degraded when training data are highly imbalanced among classes (Sage et al. 2020). Because only a small portion of the study area burns each year, a simple random sample would be dominated by unburned pixels. We therefore stratified by outcome to train the model on equal numbers of burned and unburned cases. This sampling scheme resulted in pixel-level model predictions, ranging from 0-1, that do not represent absolute probabilities of burning. However, our goal was not to estimate absolute probabilities of burning, but rather to quantify the relative probability of a large wildfire based on fuel characteristics.

We define fire probability at pixel $i$ with observed predictors $x_{i}, p_{i}=P\left(y_{i}=1 \mid x_{i}\right)$. Estimates of $p(\hat{p})$ were derived from RF classification models using tree vote aggregation (Sage et al. 2020). Each tree predicts the most probable class of the new observation ('casts a vote'), and the RF estimate of fire probability is the average vote among trees.

Training data were sampled randomly in time and space to reduce spatial and temporal autocorrelation among training data. This is particularly important for modeling a process like fire with strong spatio-temporal order; in any given fire season, the outcomes of spatially adjacent pixels are strongly interdependent. Our sampling schema ensured only a single year's observation, randomly selected from the $32 \mathrm{yr}$ time series, could be included at any given 
spatial coordinates. Thus, even when sampled pixels were in close spatial proximity, it was unlikely the observations represented by those samples were proximal in time, and vice versa.

\section{Model tuning and evaluation}

We drew a sample of $n=10,000$ pixels (5,000 each burned and unburned) for model tuning and testing. We split this sample into a training set ( $80 \%)$ and testing set ( 20\%) by selecting 6 of the 32 years at random and withholding all samples from those years to evaluate the final model. We used a two-step cross-validation procedure to determine the combination of hyperparameters ( $m_{\text {try }}$ and sampling fraction) and predictors that maximized model performance on the training set. Cross-validation folds were defined using the natural grouping structure of the data; one year's samples were withheld at a time to assess model performance.

We used recursive feature elimination (Guyon et al. 2002, Svetnik et al. 2004) to select a parsimonious subset of predictors. Recursive feature elimination (RFE) operates on rankings of variable importance, which can be compromised when predictors are highly correlated. We therefore screened highly correlated variables prior to beginning the RFE algorithm, removing variables correlated $\geq 0.9$ in order of mean correlation until all correlations were below that threshold. We then used the rfe function in the "caret" package (Kuhn 2009, 2020) to select a parsimonious subset of predictors, using RF default hyperparameters (see below) and selecting based on kappa. The tolerance was set to select the smallest subset of predictors that achieved kappa within $1.5 \%$ of the maximum among all tested subsets.

Next, we performed a grid search to select the best combination of predictors (the full set of $k$ predictors or the subset selected through RFE) and RF hyperparameters. RF defaults are to build each tree on a bootstrap sample of the training data and consider a random selection of $m=\sqrt{k}$ of the $k$ available predictors at each split $\left(m_{t r y}\right.$; Breiman 2001). We considered models with values of $m_{\text {try }}$ from $\frac{\sqrt{k}}{2}$ to $\frac{k}{3}$, and trees grown on subsamples (without replacement) of the $n$ 
training samples ranging in size from $0.1 n$ to $0.5 n$, or the default bootstrap sample (with replacement) of size $n$ (Martínez-Muñoz and Suárez 2010). We held the minimum node size and maximum number of nodes constant at values ( 1 and unlimited, respectively) recommended for probability estimation using tree vote aggregation (Liaw and Wiener 2012, Sage et al. 2020). All forests were grown to 1,250 trees.

When accurate class probabilities (e.g., relative fire probability) are the primary objective, the log-loss is a more informative performance metric than threshold-based measures such as percent correctly classified, area under the receiver operating characteristic curve (AUC), or kappa. We therefore selected as our final model the set of hyperparameters that minimized the global log-loss across years. For a predicted fire probability $\hat{p}_{i}$ and observed outcome $y_{i}$, the log-loss is defined as:

$$
L_{\log }\left(y_{i}, \hat{p}_{i}\right)=-y_{i} \log \left(\hat{p}_{i}\right)+\left(1-y_{i}\right) \log \left(1-\hat{p}_{i}\right)
$$

and the global log-loss is the average log-loss across cases. RF models were fit with the ranger function in the "ranger" package (Wright and Ziegler 2017) in R. The combination of tuning parameters and predictors that minimized the global log-loss was then evaluated on the withheld testing set and carried forward for mapping and further validation in GEE.

\section{Forecast date}

We anticipated a trade-off between accuracy and lead-time, such that forecasts made earlier in the spring, when they would potentially be more useful for planning, would be less accurate than forecasts made later in the spring. We reasoned that the short-term drought and production data would become increasingly informative as the forecast date approached the onset of the fire season, thus improving accuracy. We therefore tested forecasts made on 5 dates throughout the spring, aligning with the availability of new 16-day production estimates. These included days of year (DOY) 65 (March 6) through 145 (May 25), at 16-day intervals. As a point of reference, the median ignition date of the first large wildfire in the Great Basin from 
1988 to 2019 was May 31 (DOY = 150). We tuned models individually by forecast date, and report cross-validation model performance metrics for each forecast date.

\section{Forecast map validation}

To evaluate the model at practical scales and provide information about spatial and temporal predictive utility beyond what is provided by standard model performance metrics, we conducted a model validation based on annual maps of predicted fire probabilities. Similar to our cross-validation model tuning procedure, maps were constructed by withholding one year's data at a time, fitting the model to samples from the remaining years, and then mapping predicted probabilities for the withheld year. We evaluated spatial predictive utility by calculating burned area within bins of increasing predicted fire risk for each year and then aggregating burned area across years. Specifically, we binned continuous pixel-level estimates $\hat{p}$ into twenty equal-range ordinal bins [0-0.05], $(0.05-0.1], \ldots,(0.95-1]$ and summed the total area in each bin that burned across years. To account for the non-uniform distribution of probabilities, we calculated the total mapped area (both burned and unburned) in each bin across years and displayed the proportion of the total area burned in each bin. If model fit is adequate, the proportion burned should increase monotonically from the lowest to highest bin. We also compared the relative performance of forecast dates using a precision-recall curve based on the same ordinal bins. Considering the lower bound of each bin sequentially as prediction thresholds, precision was approximated by the sum of the area of burned pixels for which $\hat{p}>$ threshold divided by the total area for which $\hat{p}>$ threshold. Recall was approximated by the sum of the area of burned pixels for which $\hat{p}>$ threshold divided by the total area burned across bins.

To evaluate predictive utility through time, we aggregated predicted fire probability across the study area (mean) and calculated correlations between annual mean predicted fire probability and several annual metrics of fire season severity. These metrics included total area 
burned in large wildfires, number of large wildfires, mean fire size, max fire size, season onset (ignition date of the first large wildfire), and season length (number of days between season onset and ignition date of the last large wildfire). Total area burned was calculated from the MTBS thematic burn severity dataset to account for unburned inclusions within fire perimeters, while all other metrics were calculated from the MTBS fire perimeter dataset. Highly skewed variables were either square-root (areas) or log (number of fires) transformed.

Finally, we present variable importance (permutation-based mean decrease in accuracy) and partial dependence plots to visualize the effects of individual predictors on fire probability. Importance was calculated for each of the model tuning cross-validation folds, and the mean and range of importance across folds was calculated for each included predictor. Partial dependence plots were produced for the 16 predictors ranking highest in mean importance.

\section{Results}

\section{Model tuning and evaluation}

Cross-validation performance was similar across forecast dates, with the earliest forecast dates slightly outperforming others. The full set of 56 predictors outperformed the reduced set for all forecast dates except DOY 129 (Table 2). The reduced set chosen for DOY 129 included only 8 variables, all related to herbaceous cover/productivity, bare ground, or longterm moisture balance (Table S1). For all dates, models constructed by building trees with a small random subset of the training data sampled without replacement (sample fraction $=0.1$ 0.2) minimized the log-loss. Cross-validation performance was less sensitive to $m_{\text {try }}$, but larger values (9-18) performed better than random forest defaults $(\sqrt{p}=7.5)$ for models fit to the full set of predictors. Model performance on the withheld independent testing dataset was similar to performance in cross-validation, with threshold-based performance metrics (i.e., AUC, kappa) slightly improved, but log-loss slightly higher (Table 2). 


\section{Forecast map validation}

Proportional area burned increased monotonically with increasing predicted fire probability for all forecast dates except DOY 113 and 145 (Fig. 2A). Similar to cross-validation on the balanced training sample, the earliest date (DOY 65) displayed the highest skill in terms of the tradeoff between precision and recall (Fig. 2B), and the remainder of the forecast map validation results focus on that forecast date. Burned pixels were strongly skewed toward higher predicted fire probability, with $77 \%$ of the total burned area corresponding to predicted probabilities $>0.5$, which accounted for $19 \%$ of the landscape across years. Annual burned area across the Great Basin was strongly positively correlated $(\rho=0.84$, bootstrap $95 \% \mathrm{Cl}=0.68-$ 0.99) with mean predicted fire probability, which ranged from 0.13 to 0.44 (Fig. 3). The number of large wildfires was also strongly correlated $(\rho=0.74$, bootstrap $95 \% \mathrm{Cl}=0.57-0.90)$ with mean predicted fire probability. Mean fire probability was moderately correlated with max fire size $(\rho=0.66$, bootstrap $95 \% \mathrm{Cl}=0.44-0.89)$. The median fire size, onset of the fire season, and season length were only weakly correlated $(0.3<\rho<0.5)$ with mean fire probability, but in the expected direction (i.e., higher fire probability was associated with larger median fire size, earlier onset, and longer fire seasons; Fig. 3). 

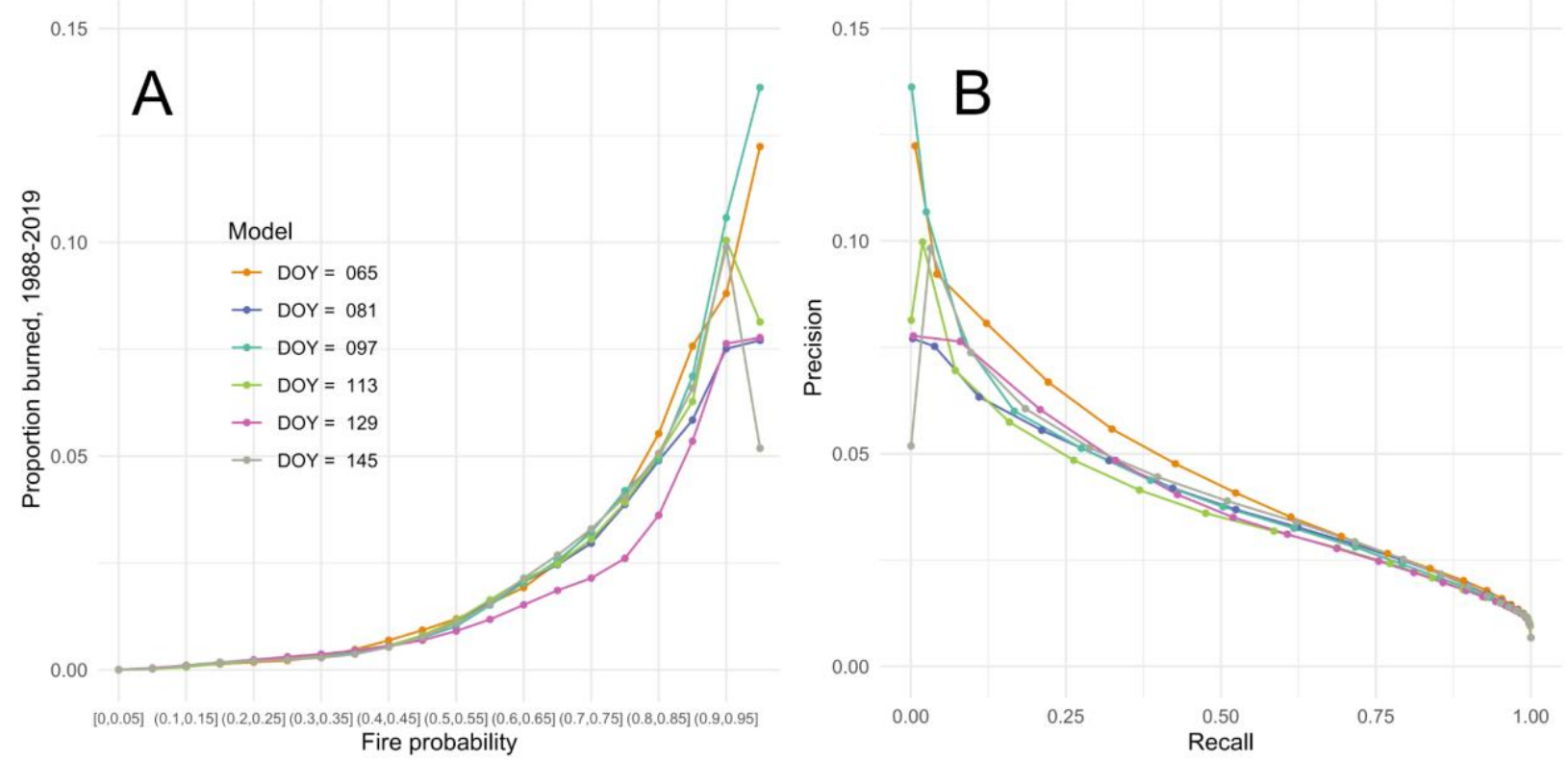

Fig. 2. Validation of fuel-based rangeland fire probability forecasts using weather and vegetation production data through the indicated day of year (DOY). Mapped continuous predictions of fire probability ranging from 0-1 were divided into 20 equal-width bins. Panel A shows the proportion of the total area in each bin across the Great Basin that burned in large wildfires from 19882019. Panel B shows the tradeoff between precision and recall (see methods for calculations). Precision is low, reflecting a high false positive rate for any prediction threshold. This is not necessarily a reflection of poor model performance; the model is based on fuels, and large wildfires inevitably will burn only a small portion of areas with adequate fuels due to absence of ignition or successful early fire suppression. The earliest forecast (DOY $=65$ : March 6) displayed the best performance in terms of the precision/recall tradeoff. 

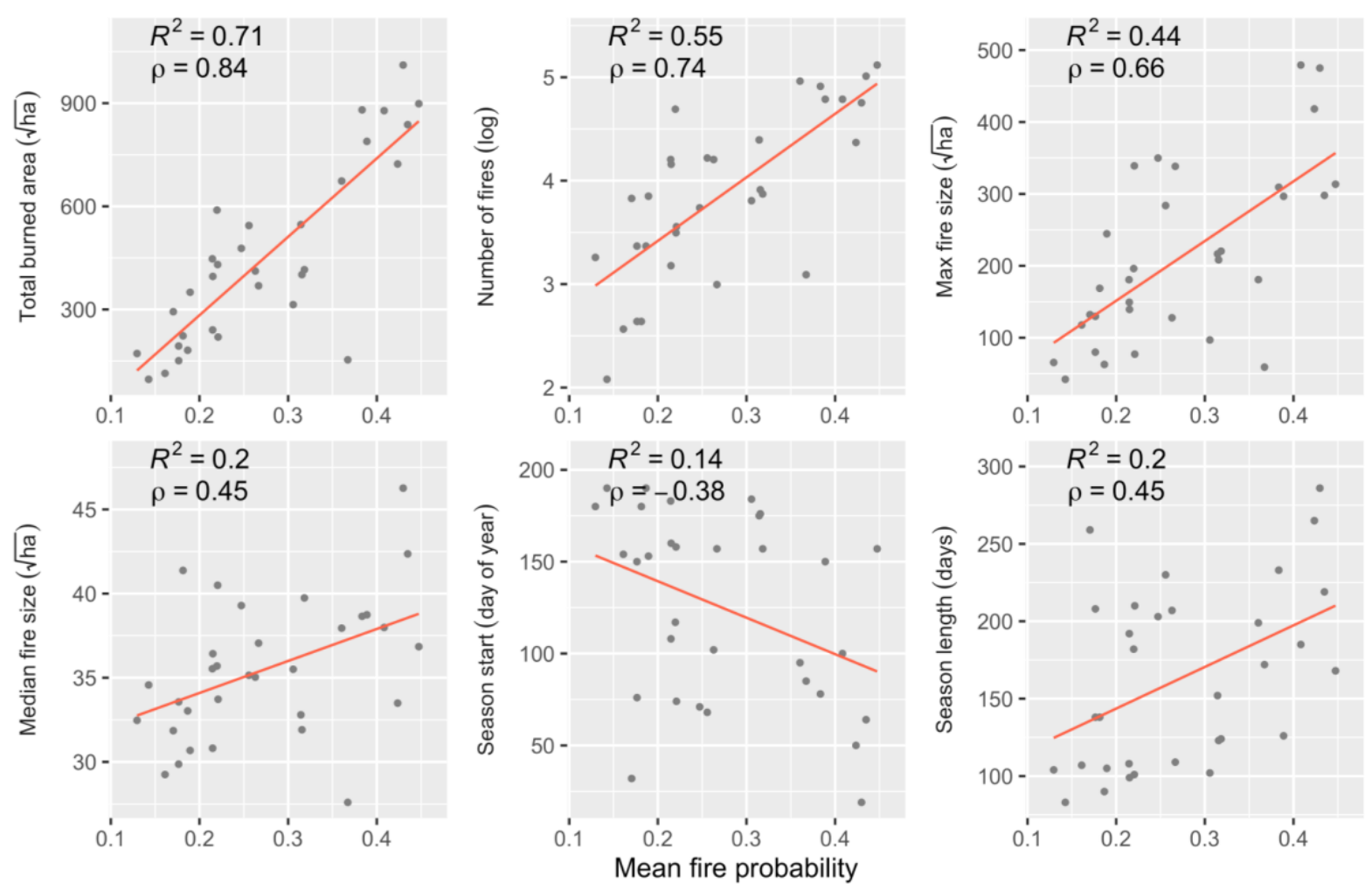

Figure 3. Metrics of wildfire season severity in the Great Basin, USA, from 1988-2019 in relation to mean fire probability. Mean fire probability was moderately to strongly correlated with the total number of fires, total area burned, and maximum fire size, and weakly correlated with median fire size, onset of the fire season, and fire season length. Fitted lines and coefficients of determination are from least squares regressions.

\section{Variable importance}

Herbaceous vegetation variables outranked all other categories in importance (Fig. 4). Nine of the 10 top-ranked predictors were biotic, including nearly all herbaceous vegetation variables at both lag-1 and lag-2 scales and bare ground cover. Perennial herbaceous cover and production ranked highly at both lag-1 and lag-2 scales, while annual herbaceous cover and production ranked highly at lag-1 but much lower at lag-2. Short-term annual grass and forb production in the spring leading up to the forecast date was also highly important. Variables related to long-term (SPEI at 2 yr scale, annual precipitation) and short-term moisture balance (EDDI at $30 \mathrm{~d}$ and $90 \mathrm{~d}$ scales) followed in importance, with intermediate-term drought indices, 
bioRxiv preprint doi: https://doi.org/10.1101/2021.06.25.449963; this version posted June 27, 2021. The copyright holder for this preprint (which was not certified by peer review) is the author/funder. All rights reserved. No reuse allowed without permission.

bioclimatic variables, trees, litter, and shrubs ranking lower. The highest ranked bioclimatic predictors were related to temperature variability: temperature seasonality (bio04) and temperature annual range (bio07). Both metrics of temperature variability were positively associated with fire probability. 
bioRxiv preprint doi: https://doi.org/10.1101/2021.06.25.449963; this version posted June 27, 2021. The copyright holder for this preprint (which was not certified by peer review) is the author/funder. All rights reserved. No reuse allowed without permission.

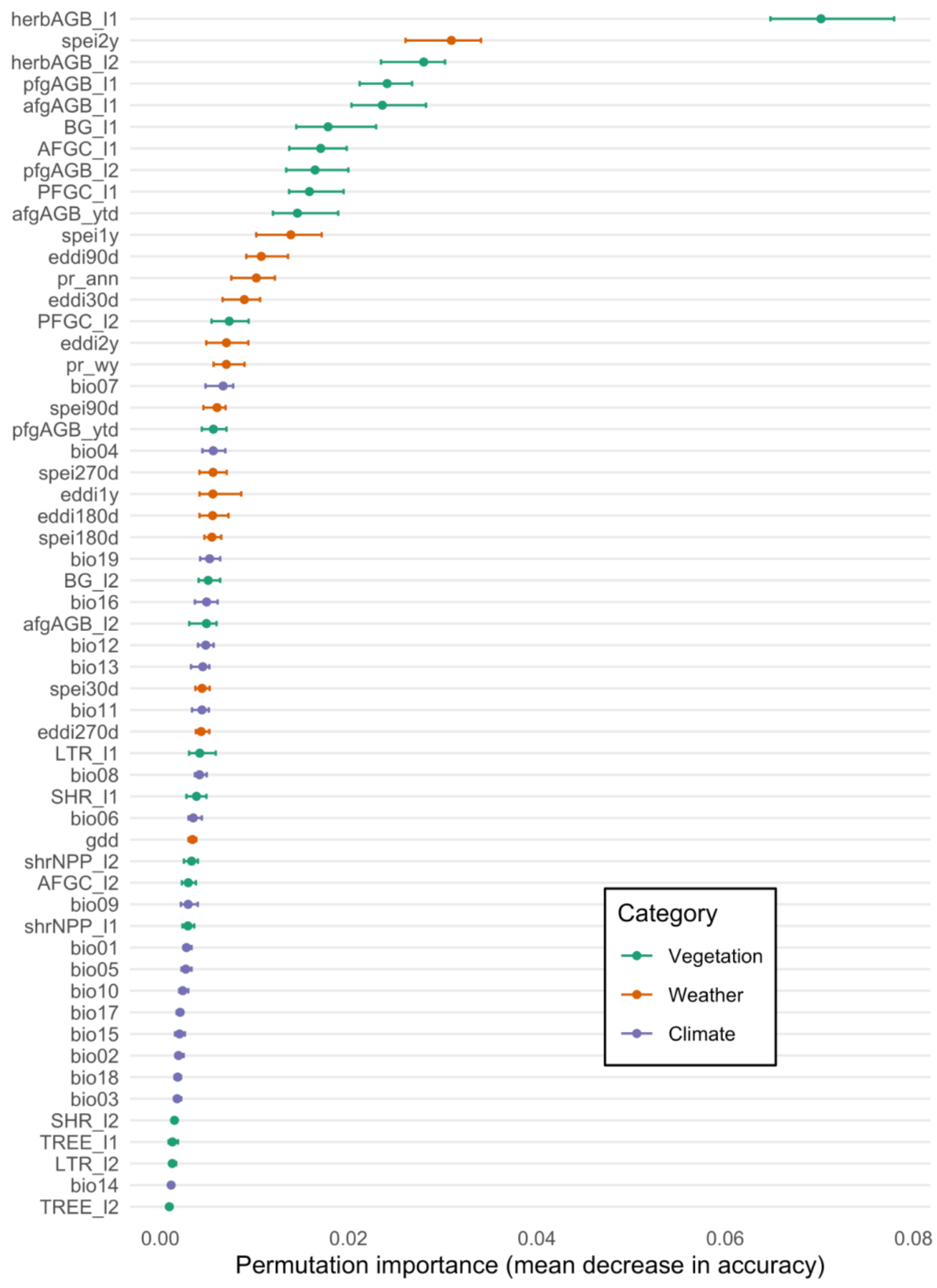

Figure 4. Importance (mean decrease in accuracy) of variables used to predict probability of fire in the Great Basin, USA, 1988-2019. The range (error bars) and mean (dot) of the index across 26 cross-validation subsets used for model tuning are shown. 


\section{Discussion}

Spatial and temporal patterns in fire activity in Great Basin rangelands over the last three decades were predicted accurately by a fire probability model based on antecedent cover and production of vegetation, weather, and multi-temporal drought indices. At the scale of the Great Basin, several annual metrics of fire season severity, including total area burned and number of large wildfires, were predictable from average fire probability alone (Fig. 3). Significantly, these spatial forecasts of fire probability are based on data available well before peak vegetation production and months before most large fires start, providing opportunity for advanced planning, implementation, and resource allocation.

The recent proliferation of very large fires across the western US has been attributed to the emerging influence of anthropogenic climate change on fire weather (Abatzoglou et al. 2019), and hotter and drier conditions over a longer fire season have been implicated in increased fire activity across ecosystems (Jolly et al. 2015, Abatzoglou and Williams 2016, Bowman et al. 2020). A trend of increasing burned area has likewise emerged in the Great

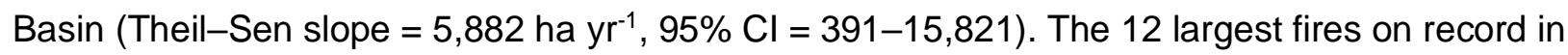
the Great Basin have all occurred since 2000, with 8 of those having occurred since 2010. Although we cannot rule out an influence of intensifying fire weather, it is noteworthy that recent years of exceptional fire activity in the Great Basin (e.g., 2006, 2012, 2017, and 2018) were predictable on the basis of fuels (Fig. S1). Increasing cover (Theil-Sen slope $=0.26 \% \mathrm{yr}^{-1}, 95 \%$ $\mathrm{Cl}=0.16-0.37$ ) and production (Theil-Sen slope $=4.1 \mathrm{~kg} \mathrm{ha}^{-1} \mathrm{yr}^{-1}$ aboveground biomass, 95\% $\mathrm{Cl}=2.5-5.5$ ) of annual forbs and grasses and declining bare ground (Theil-Sen slope $=-0.14 \%$ $\left.\mathrm{yr}^{-1}, 95 \% \mathrm{Cl}=-0.22--0.05\right)$ have contributed to a significant increase in average fire probability over the past three decades. Although it is beyond the scope of this analysis to explain trends in fire activity in the Great Basin, these changes in fuel characteristics, and the resulting increasing trend in fire probability, leave little doubt that fuels have played a large role in the recent upturn. 
The predictive skill of these models speaks to the extent to which fire is controlled by herbaceous fuel quantity, as opposed to fuel moisture or fire weather, in Great Basin rangelands. This is consistent with past research (e.g., Pilliod et al. 2017) and suggests fuel management holds potential to mitigate risk of wildfire disasters. We acknowledge, however, that fire weather can also be influential, especially in the outcomes of individual fires. We also note that some of the shorter-term drought indices we included may be serving as proxies for fuel moisture. For example, the opposing effects of SPEI and EDDI at longer (e.g., 2 yr) and shorter (e.g., $90 \mathrm{~d}, 30 \mathrm{~d}$ ) temporal scales indicates fire probability peaks when a dry winter/early spring follows a long-term moisture surplus (Fig. 5). This suggests the emergence of a moisture deficit in the spring promotes fire, likely by hastening the drying of herbaceous fuels. Notable outliers in the regression of burned area on mean fire probability, in which the total area burned was well below expectations, include years characterized by particularly wet late spring and summer conditions (e.g., 1997; Fig. S1). Nevertheless, the ascendancy of fuel quantity in controlling fire is reinforced by the far greater importance of previous years' herbaceous biomass production and cover and variables related to long-term (1-2 yr) water balance (Fig. 4). Moreover, reducing the forecast lead time to include information about short-term herbaceous production and weather immediately preceding the onset of the fire season diminished, rather than improved, forecast performance. 

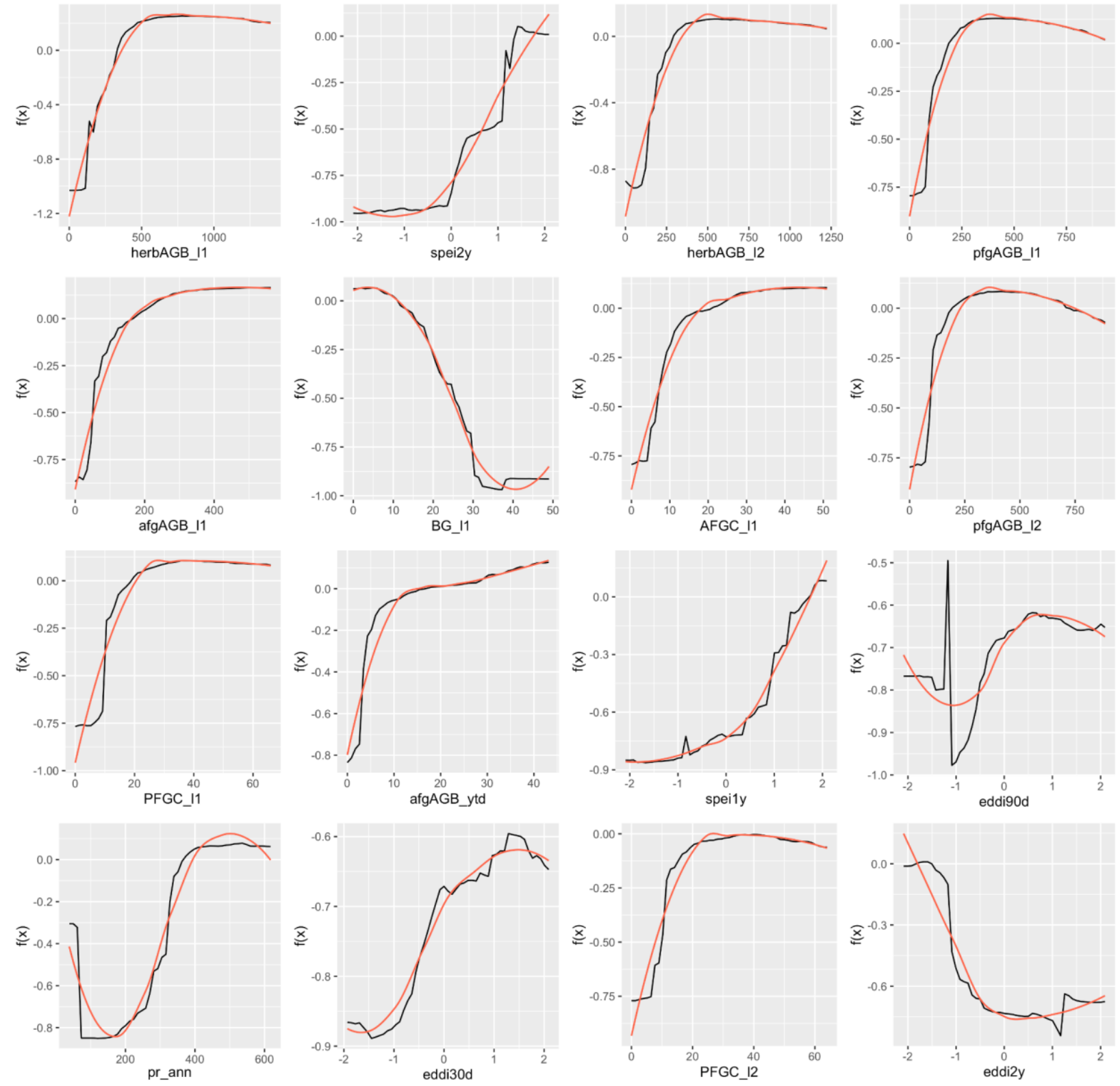

Figure 5. Effects of the top 16 predictors of fire probability ranked by importance. Black lines show the partial dependence function $f(x)$ (centered logit of fire probability), with the general shape of the relationship highlighted with a LOESS smoother (span $=0.75$; red lines).

Although intense interest has attended the role of exotic annual grasses in fueling large fires in the Great Basin and throughout the western US (Balch et al. 2013, Davies and Nafus 2013, Fusco et al. 2019), perennial grasses and forbs ranked about equally in importance in our models (Fig. 4). The highest variable importance was attributed to total herbaceous 
aboveground biomass, suggesting that the composition of fine fuels is less critical than the quantity. The ultimate influence of annuals on fire probability may be at least partly expressed in the negative effect of bare ground-among the top-rated variables by importance. Bare ground is more strongly negatively correlated with cover and production of annuals than cover and production of perennials (data not shown), and temporal patterns in bare ground are a virtual mirror image of patterns in annual forb and grass cover. By occupying what would otherwise be bare ground, annuals may act as ladder fuels that help ignite and connect the larger and more volatile fuels represented by perennials and shrubs (Davies and Nafus 2013), which make up the large majority of biomass in most places. While there is little doubt exotic annual grasses have increased flammability and reduced fire return intervals in Great Basin rangelands (Balch et al. 2013), macro-scale spatio-temporal patterns of fire activity remain strongly controlled by weather-driven variation in productivity of perennial herbaceous vegetation (Pilliod et al. 2017).

\section{Implications}

Although fuels exert strong control on fire in the Great Basin, other factors such as extreme fire weather and national-scale demand on resources still play an important role in the outcomes of individual fires and fire seasons. Antecedent weather-driven peaks in fuel loading, coincident with extreme fire weather across western North America, are likely to continue to overcome suppression resources and cause wildfire disasters. However, fine-scale spatial fire probability forecasts such as those developed here may help managers anticipate and mitigate such events. Managers monitor a suite of indicators of fire danger, including drought indices, snowpack, long-term weather outlooks, and vegetation monitoring data as the fire season approaches. Because these indicators vary widely in spatial and temporal grain and extent, their integration into a coherent picture of the regional distribution of fuels leading into the fire season remains challenging, particularly at sub-ecoregional scales. A major contribution of the framework we present here is that it integrates many of the indicators already widely used by 
managers into a single predictive metric applicable across a broad range of spatial scales, from the pixel to the ecoregion (Fig. 6). Used alongside short-term fire danger indices and other tools, these forecasts may help managers more accurately predict and prepare for where and when ignitions are likely to result in expensive, dangerous, and ecologically damaging large wildfires.

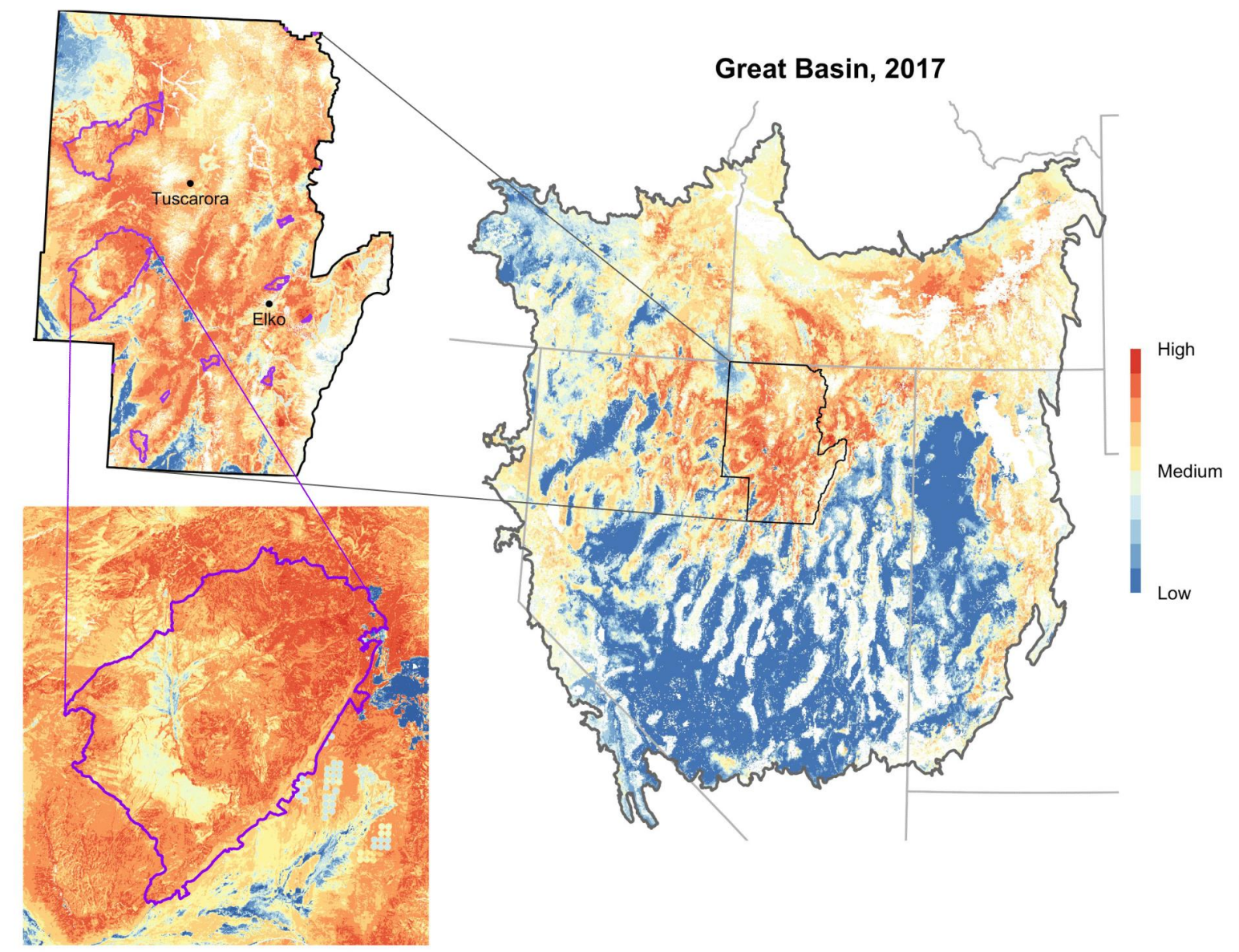

Figure 6. 2017 fire probability in the Great Basin, USA. Insets highlight the applicability across a range of spatial scales. Used in conjunction with fire danger indices, other fire forecasts, and expert knowledge, seasonal fire probability maps may help managers at multiple levels prepare for where and when ignitions are likely to result in large and damaging wildfires. Perimeters of wildfires $>400$ ha that occurred in 2017 are depicted in purple within the insets. 


\section{Literature Cited}

Abatzoglou, J. T. 2013. Development of gridded surface meteorological data for ecological applications and modelling. International Journal of Climatology 33:121-131.

Abatzoglou, J. T., C. S. Juang, A. P. Williams, C. A. Kolden, and A. L. Westerling. 2021. Increasing synchronous fire danger in forests of the western United States. Geophysical Research Letters 48:1-9.

Abatzoglou, J. T., and C. A. Kolden. 2013. Relationships between climate and macroscale area burned in the western United States. International Journal of Wildland Fire 22:10031020.

Abatzoglou, J. T., and A. P. Williams. 2016. Impact of anthropogenic climate change on wildfire across western US forests. Proceedings of the National Academy of Sciences of the United States of America 113:11770-11775.

Abatzoglou, J. T., A. P. Williams, and R. Barbero. 2019. Global emergence of anthropogenic climate change in fire weather indices. Geophysical Research Letters 46:326-336.

Abatzoglou, J. T., A. P. Williams, L. Boschetti, M. Zubkova, and C. A. Kolden. 2018. Global patterns of interannual climate-fire relationships. Global Change Biology 24:5164-5175.

Allred, B. W., B. T. Bestelmeyer, C. S. Boyd, C. Brown, K. W. Davies, M. C. Duniway, L. M. Ellsworth, T. A. Erickson, S. D. Fuhlendorf, T. V. Griffiths, V. Jansen, M. O. Jones, J. Karl, A. Knight, J. D. Maestas, J. J. Maynard, S. E. McCord, D. E. Naugle, H. D. Starns, D. Twidwell, and D. R. Uden. 2021. Improving Landsat predictions of rangeland fractional cover with multitask learning and uncertainty. Methods in Ecology and Evolution 12:841-849.

Balch, J. K., B. A. Bradley, J. T. Abatzoglou, R. C. Nagy, E. J. Fusco, and A. L. Mahood. 2017. Human-started wildfires expand the fire niche across the United States. Proceedings of the National Academy of Sciences of the United States of America 114:2946-2951. 
Balch, J. K., B. A. Bradley, C. M. D’Antonio, and J. Gómez-Dans. 2013. Introduced annual grass increases regional fire activity across the arid western USA (1980--2009). Global Change Biology 19:173-183.

Balch, J. K., T. Schoennagel, A. P. Williams, J. T. Abatzoglou, M. E. Cattau, N. P. Mietkiewicz, and L. A. St. Denis. 2018. Switching on the Big Burn of 2017. Fire 1:17.

Bowman, D. M. J. S., C. A. Kolden, J. T. Abatzoglou, F. H. Johnston, G. R. van der Werf, and M. Flannigan. 2020. Vegetation fires in the Anthropocene. Nature Reviews Earth \& Environment 1:500-515.

Breiman, L. 2001. Random forests. Machine learning 45:5-32.

Brown, K. J., J. S. Clark, E. C. Grimm, J. J. Donovan, P. G. Mueller, B. C. S. Hansen, and I. Stefanova. 2005. Fire cycles in North American interior grasslands and their relation to prairie drought. Proceedings of the National Academy of Sciences of the United States of America 102:8865-8870.

Burgan, R. E., R. W. Klaver, and J. M. Klaver. 1998. Fuel models and fire potential from satellite and surface observations. International Journal of Wildland Fire 8:159-170.

Churkina, G., and S. W. Running. 1998. Contrasting climatic controls on the estimated productivity of global terrestrial biomes. Ecosystems 1:206-215.

Coates, P. S., M. A. Ricca, B. G. Prochazka, M. L. Brooks, K. E. Doherty, T. Kroger, E. J. Blomberg, C. A. Hagen, and M. L. Casazza. 2016. Wildfire, climate, and invasive grass interactions negatively impact an indicator species by reshaping sagebrush ecosystems. Proceedings of the National Academy of Sciences 113:12745-12750.

Coop, J. D., S. A. Parks, C. S. Stevens-Rumann, S. D. Crausbay, P. E. Higuera, M. D. Hurteau, A. Tepley, E. Whitman, T. Assal, B. M. Collins, K. T. Davis, S. Dobrowski, D. A. Falk, P. J. Fornwalt, P. Z. Fulé, B. J. Harvey, V. R. Kane, C. E. Littlefield, E. Q. Margolis, M. North, M.-A. Parisien, S. Prichard, and K. C. Rodman. 2020. Wildfire-driven forest conversion in western North American landscapes. Bioscience 70:659-673. 
Cutler, D. R., T. C. Edwards Jr, K. H. Beard, A. Cutler, K. T. Hess, J. Gibson, and J. J. Lawler. 2007. Random forests for classification in ecology. Ecology 88:2783-2792.

D’Antonio, C. M., and P. M. Vitousek. 1992. Biological invasions by exotic grasses, the grass/fire cycle, and global change. Annual Review of Ecology and Systematics 23:6387.

Davies, K. W., and A. M. Nafus. 2013. Exotic annual grass invasion alters fuel amounts, continuity and moisture content. International Journal of Wildland Fire 22:353-358.

Dennison, P. E., S. C. Brewer, J. D. Arnold, and M. A. Moritz. 2014. Large wildfire trends in the western United States, 1984--2011. Geophysical Research Letters 41:2928-2933.

Eidenshink, J., B. Schwind, K. Brewer, Z.-L. Zhu, B. Quayle, and S. Howard. 2007. A project for monitoring trends in burn severity. Fire Ecology 3:3-21.

Fusco, E. J., J. T. Finn, J. K. Balch, R. C. Nagy, and B. A. Bradley. 2019. Invasive grasses increase fire occurrence and frequency across US ecoregions. Proceedings of the National Academy of Sciences 116:23594-23599.

Gorelick, N., M. Hancher, M. Dixon, S. Ilyushchenko, D. Thau, and R. Moore. 2017. Google Earth Engine: Planetary-scale geospatial analysis for everyone. Remote Sensing of Environment 202:18-27.

Guyon, I., J. Weston, S. Barnhill, and V. Vapnik. 2002. Gene selection for cancer classification using Support Vector Machines. Machine Learning 46:389-422.

Hijmans, R. J., S. E. Cameron, J. L. Parra, P. G. Jones, and A. Jarvis. 2005. Very high resolution interpolated climate surfaces for global land areas. International Journal of Climatology 25:1965-1978.

Hobbins, M. T., A. Wood, D. J. McEvoy, J. L. Huntington, C. Morton, M. Anderson, and C. Hain. 2016. The Evaporative Demand Drought Index. Part I: linking drought evolution to variations in evaporative demand. Journal of Hydrometeorology 17:1745-1761. 
Jolly, W. M., M. A. Cochrane, P. H. Freeborn, Z. A. Holden, T. J. Brown, G. J. Williamson, and D. M. J. S. Bowman. 2015. Climate-induced variations in global wildfire danger from 1979 to 2013. Nature Communications 6:7537.

Jones, M. O., B. W. Allred, D. E. Naugle, J. D. Maestas, P. Donnelly, L. J. Metz, J. Karl, R. Smith, B. Bestelmeyer, C. Boyd, J. D. Kerby, and J. D. Mclver. 2018. Innovation in rangeland monitoring: annual, $30 \mathrm{~m}$, plant functional type percent cover maps for U.S. rangelands, 1984-2017. Ecosphere 9:e02430.

Jones, M. O., N. P. Robinson, D. E. Naugle, J. D. Maestas, M. C. Reeves, R. W. Lankston, and B. W. Allred. 2021. Annual and 16-day rangeland production estimates for the western United States. Rangeland Ecology \& Management 77:112-117.

Keetch, J. J., and G. M. Byram. 1968. A drought index for forest fire control. U.S. Department of Agriculture, Forest Service, Southeastern Forest Experiment Station.

Knick, S. T., D. S. Dobkin, J. T. Rotenberry, M. A. Schroeder, W. M. V. Haegen, and C. van Riper III. 2003. Teetering on the edge or too late? Conservation and research issues for avifauna of sagebrush habitats. The Condor 105:611-634.

Kolden, C. A., J. A. Lutz, C. H. Key, J. T. Kane, and J. W. van Wagtendonk. 2012. Mapped versus actual burned area within wildfire perimeters: Characterizing the unburned. Forest Ecology and Management 286:38-47.

Krawchuk, M. A., and M. A. Moritz. 2011. Constraints on global fire activity vary across a resource gradient. Ecology 92:121-132.

Kuhn, M. 2009. Building predictive models in $\mathrm{R}$ using the caret package. Journal of Statistical Software 28:1-26.

Kuhn, M. 2020. caret: Classification and Regression Training. https://CRAN.Rproject.org/package=caret.

Liaw, A., and M. Wiener. 2012. Package "randomForest": Breiman and Cutler's random forests for classification and regression. CRAN. https://CRAN.R-project.org 
Littell, J. S., D. McKenzie, D. L. Peterson, and A. L. Westerling. 2009. Climate and wildfire area burned in western U.S. ecoprovinces, 1916-2003. Ecological applications: a publication of the Ecological Society of America 19:1003-1021.

Marlon, J. R., P. J. Bartlein, D. G. Gavin, C. J. Long, R. S. Anderson, C. E. Briles, K. J. Brown, D. Colombaroli, D. J. Hallett, M. J. Power, E. A. Scharf, and M. K. Walsh. 2012. Longterm perspective on wildfires in the western USA. Proceedings of the National Academy of Sciences of the United States of America 109:E535-43.

Martínez-Muñoz, G., and A. Suárez. 2010. Out-of-bag estimation of the optimal sample size in bagging. Pattern Recognition 43:143-152.

McEvoy, D. J., J. L. Huntington, M. T. Hobbins, A. Wood, C. Morton, M. Anderson, and C. Hain. 2016. The Evaporative Demand Drought Index. Part II: CONUS-wide assessment against common drought indicators. Journal of Hydrometeorology 17:1763-1779.

Niculescu-Mizil, A., and R. Caruana. 2005. Predicting good probabilities with supervised learning. Pages 625-632 Proceedings of the 22nd international conference on Machine learning. Association for Computing Machinery, New York, NY, USA.

Noss, R. F., J. F. Franklin, W. L. Baker, T. Schoennagel, and P. B. Moyle. 2006. Managing fireprone forests in the western United States. Frontiers in Ecology and the Environment $4: 481-487$.

Oliveira, S., F. Oehler, J. San-Miguel-Ayanz, A. Camia, and J. M. C. Pereira. 2012. Modeling spatial patterns of fire occurrence in Mediterranean Europe using multiple regression and random forest. Forest Ecology and Management 275:117-129.

Omernik, J. M., and G. E. Griffith. 2014. Ecoregions of the conterminous United States: evolution of a hierarchical spatial framework. Environmental Management 54:12491266. 
O’Neil, S. T., P. S. Coates, B. E. Brussee, M. A. Ricca, S. P. Espinosa, S. C. Gardner, and D. J. Delehanty. 2020. Wildfire and the ecological niche: diminishing habitat suitability for an indicator species within semi-arid ecosystems. Global Change Biology 26:6296-6312.

Palmer, W. C. 1965. Meteorological Drought. U.S. Department of Commerce, Weather Bureau.

Pilliod, D. S., J. L. Welty, and R. S. Arkle. 2017. Refining the cheatgrass-fire cycle in the Great Basin: Precipitation timing and fine fuel composition predict wildfire trends. Ecology and Evolution 7:8126-8151.

Podur, J., and M. Wotton. 2010. Will climate change overwhelm fire management capacity? Ecological Modelling 221:1301-1309.

Reeves, M. C., and J. E. Mitchell. 2011. Extent of coterminous US rangelands: Quantifying implications of differing agency perspectives. Rangeland Ecology \& Management 64:585-597.

Rockweit, J. T., A. B. Franklin, and P. C. Carlson. 2017. Differential impacts of wildfire on the population dynamics of an old-forest species. Ecology 98:1574-1582.

Sage, A. J., U. Genschel, and D. Nettleton. 2020. Tree aggregation for random forest class probability estimation. Statistical Analysis and Data Mining 13:134-150.

Svetnik, V., A. Liaw, C. Tong, and T. Wang. 2004. Application of Breiman's random forest to modeling structure-activity relationships of pharmaceutical molecules. Pages 334-343 Multiple Classifier Systems. Springer Berlin Heidelberg, Berlin, Heidelberg.

Vicente-Serrano, S. M., S. Beguería, and J. I. López-Moreno. 2010. A multiscalar drought index sensitive to global warming: The Standardized Precipitation Evapotranspiration Index. Journal of Cimate 23:1696-1718.

Westerling, A. L. 2016. Increasing western US forest wildfire activity: sensitivity to changes in the timing of spring. Philosophical transactions of the Royal Society of London. Series B, Biological sciences 371 . 
Westerling, A. L., A. Gershunov, T. J. Brown, D. R. Cayan, and M. D. Dettinger. 2003. Climate and wildfire in the western United States. Bulletin of the American Meteorological Society 84:595-604.

Westerling, A. L., A. Gershunov, D. R. Cayan, and T. P. Barnett. 2002. Long lead statistical forecasts of area burned in western US wildfires by ecosystem province. International Journal of Wildland Fire 11:257-266.

Wright, M. N., and A. Ziegler. 2017. ranger: A fast implementation of random forests for high dimensional data in $\mathrm{C}++$ and $\mathrm{R}$. Journal of Statistical Software 77:1-17. 


\section{Tables}

Table 1. Predictors used in random forest models of large rangeland wildfire occurrence in the Great Basin, USA, 1988-2019.

\begin{tabular}{|c|c|c|c|c|}
\hline Predictor & Abbreviation & $\begin{array}{l}\text { Spatial } \\
\text { resolution }\end{array}$ & Temporal scale(s) & Source ${ }^{2}$ \\
\hline Annual forb and grass cover & AFGC & $30 \mathrm{~m}$ & $\begin{array}{l}\text { Annual, lag-1 and lag- } \\
2\end{array}$ & 1 \\
\hline Perennial forb and grass cover & PFGC & $30 \mathrm{~m}$ & $\begin{array}{l}\text { Annual, lag-1 and lag- } \\
2\end{array}$ & 1 \\
\hline Shrub cover & SHR & $30 \mathrm{~m}$ & $\begin{array}{l}\text { Annual, lag-1 and lag- } \\
2\end{array}$ & 1 \\
\hline Litter cover & LTR & $30 \mathrm{~m}$ & $\begin{array}{l}\text { Annual, lag-1 and lag- } \\
2\end{array}$ & 1 \\
\hline Bare ground cover & $B G$ & $30 \mathrm{~m}$ & $\begin{array}{l}\text { Annual, lag-1 and lag- } \\
2\end{array}$ & 1 \\
\hline Tree cover & TREE & $30 \mathrm{~m}$ & $\begin{array}{l}\text { Annual, lag-1 and lag- } \\
2\end{array}$ & 1 \\
\hline $\begin{array}{l}\text { Annual forb and grass aboveground } \\
\text { biomass production }\end{array}$ & $\operatorname{afg} A G B$ & $30 \mathrm{~m}$ & $\begin{array}{l}\text { Annual, lag-1 and lag- } \\
2\end{array}$ & 2 \\
\hline $\begin{array}{l}\text { Perennial forb and grass aboveground } \\
\text { biomass production }\end{array}$ & $\operatorname{pfg} A G B$ & $30 \mathrm{~m}$ & $\begin{array}{l}\text { Annual, lag-1 and lag- } \\
2\end{array}$ & 2 \\
\hline $\begin{array}{l}\text { Herbaceous aboveground biomass } \\
\text { production }\end{array}$ & herbAGB & $30 \mathrm{~m}$ & $\begin{array}{l}\text { Annual, lag-1 and lag- } \\
2\end{array}$ & 2 \\
\hline Shrub net primary production & shrNPP & $30 \mathrm{~m}$ & $\begin{array}{l}\text { Annual, lag-1 and lag- } \\
2\end{array}$ & 2 \\
\hline $\begin{array}{l}\text { Cumulative } 16-d \text { annual forb and grass } \\
\text { aboveground biomass production }\end{array}$ & afgAGB_ytd & $30 \mathrm{~m}$ & Jan 1-forecast DOY & 2 \\
\hline $\begin{array}{l}\text { Cumulative } 16-d \text { perennial forb and grass } \\
\text { aboveground biomass production }\end{array}$ & pfgAGB_ytd & $30 \mathrm{~m}$ & Jan 1-forecast DOY & 2 \\
\hline $\begin{array}{l}\text { Standardized Precipitation- } \\
\text { Evapotranspiration Index }\end{array}$ & spei & $4 \mathrm{~km}$ & $\begin{array}{l}30 \mathrm{~d}, 90 \mathrm{~d}, 180 \mathrm{~d}, 270 \\
\mathrm{~d}, 1 \mathrm{yr}, 2 \mathrm{yr}\end{array}$ & 3 \\
\hline Evaporative Demand Drought Index & eddi & $4 \mathrm{~km}$ & $\begin{array}{l}30 \mathrm{~d}, 90 \mathrm{~d}, 180 \mathrm{~d}, 270 \\
\mathrm{~d}, 1 \mathrm{yr}, 2 \mathrm{yr}\end{array}$ & 3 \\
\hline Precipitation & $\mathrm{pr}$ & $4 \mathrm{~km}$ & $\begin{array}{l}\text { Annual (ann) and } \\
\text { water year to date (wy) }\end{array}$ & 4 \\
\hline Cumulative growing degree days & gdd & $4 \mathrm{~km}$ & Jan 1-forecast DOY & 4 \\
\hline Bioclimatic variables & bio01-bio19 & $1 \mathrm{~km}$ & & 5 \\
\hline
\end{tabular}

${ }^{1}$ All data were resampled to $120 \mathrm{~m}$ resolution for model fitting and prediction.

2Sources: 
1: Rangeland Analysis Platform (RAP) fractional cover dataset (Jones et al. 2018, Allred et al. 2021).

2: RAP annual and 16-day production dataset (Jones et al. 2021)

3: gridMET Drought Indices; University of California Merced (Abatzoglou 2013).

4: gridMET; University of California Merced (Abatzoglou 2013)

5: WorldClim; Hijmans et al. (2005) 
Table 2. Model tuning and evaluation of fuel-based rangeland fire probability models using concurrent year's precipitation, growing degree days, and cumulative vegetation production through the indicated day of year (DOY).

\begin{tabular}{|c|c|c|c|c|c|c|c|c|c|}
\hline \multirow[b]{2}{*}{ DOY } & \multirow[b]{2}{*}{$m_{\text {try }}^{1}$} & \multirow[b]{2}{*}{$\begin{array}{l}\text { Sample } \\
\text { fraction }^{2}\end{array}$} & \multirow[b]{2}{*}{ Predictors $^{3}$} & \multicolumn{3}{|c|}{ Cross-validation } & \multicolumn{3}{|c|}{ Independent testing data } \\
\hline & & & & AUC & Kappa & log-loss & AUC & Kappa & log-loss \\
\hline 65 & 12 & 0.2 & 1 & 0.873 & 0.555 & 0.445 & 0.880 & 0.599 & 0.460 \\
\hline 81 & 18 & 0.1 & 1 & 0.869 & 0.554 & 0.450 & & & \\
\hline 97 & 9 & 0.1 & 1 & 0.856 & 0.529 & 0.468 & & & \\
\hline 113 & 9 & 0.1 & 1 & 0.849 & 0.505 & 0.474 & & & \\
\hline 129 & 2 & 0.1 & 2 & 0.854 & 0.536 & 0.458 & & & \\
\hline 145 & 15 & 0.1 & 1 & 0.862 & 0.543 & 0.462 & & & \\
\hline
\end{tabular}

1 The RF hyperparameter $m_{\text {try }}$ controls the number of predictors randomly selected to consider at each split for building trees.

${ }^{2}$ Sample fraction refers to the fraction of training cases subsampled to train each tree.

3 Two candidate sets of predictors were considered: 1 = full set of 56 predictors (Table 1, Table S1), 2 = subset of predictors chosen via recursive feature elimination (see methods). 